\title{
EDITORIAL
}

\section{Capacity Assessment, Successful Aging and Geriatric Humanities}

DOI:http://dx.doi.org/10.5770/cgj.18.194

Welcome to the first issue of the Canadian Geriatrics Journal for 2015! In this issue we explore an eclectic range of topics related to both geriatrics and gerontology.

Dr. Cosco comments on the overlapping/opposing paradigms of successful aging and frailty, while Dr. Marshall et al. examines the use (and underuse) of a comprehensive geriatric assessment tool in long-term care. Dr. Frank explores his views on the use of 'geriatric humanities' to both teach and recruit future geriatricians. Dr. Patil presents a study examining the prevalence of different oral lesions in a geriatric Indian population. Dr. Parmar et al. provides an in-depth look at an iterative survey process to develop a decision-making capacity assessment model.

I wish all our subscribers every success in 2015.

Dr. Kenneth M. Madden Editor-in-Chief Canadian Geriatrics Journal 